\title{
Unconscious Bias, Racism, and Trauma-Informed Policing: an Address and Message to the Connecticut Racial Profiling Prohibition Project Advisory Board
}

\author{
Cato T. Laurencin $1,2,3,4,5,6$
}

Received: 7 May 2020 / Revised: 7 May 2020 / Accepted: 27 May 2020 / Published online: 8 June 2020

(C) W. Montague Cobb-NMA Health Institute 2020

\begin{abstract}
As a community member of the Connecticut Racial Profiling Prohibition Project Advisory Board, I wish to acknowledge the group for its work, but to make clear there is much more to be done. While the state's data show more parity across departments, we know that unconscious bias and racism still exists. I wish to advocate for the committee's work to focus on answering three new questions.
\end{abstract}

1. How does the community feel about its relationship with the police?

2. How do those who are stopped by the police feel about their experience?

3. To what extent do the police understand the principles of unconscious bias, racism, and trauma-informed policing? How effectively do they use that knowledge to help work with communities in policing?

Keywords Police $\cdot$ Policing $\cdot$ Unconscious $\cdot$ Bias $\cdot$ Racism $\cdot$ Trauma $\cdot$ Informed $\cdot$ Racial $\cdot$ Profiling

\section{Introduction}

I want to first acknowledge the group for its work on describing traffic stop analyses and findings [1]. I believe the important work has involved engaging police departments across the state to understand the data, and to make use of it to THEIR benefit and to the benefit of the people they serve.

There is much positive in the report. However, there is still much to do.

Cato T. Laurencin

laurencin@uchc.edu

1 Connecticut Convergence Institute for Translation in Regenerative Engineering, University of Connecticut Health Center, UConn Health 263 Farmington Avenue L7036, Farmington, CT 06030, USA

2 Raymond and Beverly Sackler Center for Biomedical, Biological, Physical and Engineering Sciences, UConn Health 263 Farmington Avenue L7036, Farmington, CT 06030, USA

3 Department of Orthopaedic Surgery, University of Connecticut Health Center, UConn Health 263 Farmington Avenue L7036, Farmington, CT 06030, USA

\section{Background}

First, data show discretionary stops by police in Connecticut (sometimes called pretext stops) are twice as high for Blacks than Whites with no scientific evidence or information to justify the difference in rates [1]. Second, while there is more parity among the many police departments across the state in stop data for Blacks, Latinos, and Whites, implying a society that is moving toward fairness, we know that unconscious bias

4 Department of Materials Science \& Engineering, University of Connecticut, UConn Health 263 Farmington Avenue L7036, Farmington, CT 06030, USA

5 Department of Biomedical Engineering, University of Connecticut, UConn Health 263 Farmington Avenue L7036,

Farmington, CT 06030, USA

Department of Chemical \& Biomolecular Engineering, University of Connecticut, UConn Health 263 Farmington Avenue L7036, Farmington, CT 06030, USA 
and racism continue. Moreover, I ask, what is the perception of the people in the community? What is the perception of the people stopped by police?

Why is perception important? As you may know, I recently wrote a paper called "Racial Profiling as a Public Health Issue" [2]. The paper details how racial profiling, or even the mere perception of racial profiling, can translate to detrimental medical, emotional, and physical effects [2].

As the community member of the Advisory Board, I wish to advocate for the committee's work to focus on answering three new questions.

1. How does the community feel about its relationship with the police?

2. How do those who are stopped by the police feel about their experience?

3. To what extent do the police understand the principles of unconscious bias, racism $[3,4]$, and trauma-informed policing $[5,6]$ ? How effectively is that knowledge used to help them work with communities in policing?

Many of these steps are paralleled in the medical community. Individuals in contact with our health care providers are polled after their encounter or yearly to gain their perceptions and perspectives on their experience. We should do the same for law enforcement. We in the medical profession have recognized unconscious bias and racism as real [3, 4], highly prevalent, and a hindrance to ensuring adequate care for Black and Brown people. In fact, the disproportionate impact of COVID-19 in the Black community is partially rooted in the unconscious bias and racism we see in the medical system [7, 8]. Unconscious bias and racism is also present in policing and should be addressed. We have greatly benefited in gaining perception from our patients. It has not only improved our relationships but also improved our quality of service and care.

Finally, I have alluded to the principles of trauma-informed policing [2]. Trauma-informed policing is defined as a framework for police officers to recognize and appropriately address the complexities of trauma experienced by survivors of racial profiling in policing, to acknowledge symptoms, and to use response tactics accordingly to prevent further individual trauma [2].

\section{Conclusion}

In sum, I am honored to be a part of the committee. I hope we can not only continue this current work but also expand to gain perspectives and input from the community at large and those who are stopped by police. May we lead in developing statewide approaches to address unconscious bias and racism and promote trauma-informed policing.

\section{Compliance with Ethical Standards}

Conflict of Interest The authors declare that they have no conflict of interest.

Ethical Approval This article does not contain any studies with human participants or animals performed by any of the authors.

Informed Consent Not applicable.

\section{References}

1. 2018 Traffic Stop Data Analysis and Findings Report Release Reports. n.d. Retrieved May 6, 2020, from http://www.ctrp3.org/reports/.

2. Laurencin CT, Walker JM. Racial profiling is a public health and health disparities issue. J Racial Ethn Health Disparities. 2020. https://doi.org/10.1007/s40615-020-00738-2.

3. Maina IW, Belton TD, Ginzberg S, Singh A, Johnson TJ. A decade of studying implicit racial/ethnic bias in healthcare providers using the implicit association test. Soc Sci Med. 2018;199:219-29. https:// doi.org/10.1016/j.socscimed.2017.05.009.

4. Smedley BD, Stith AY, Nelson AR. Unequal treatment: confronting racial and ethnic disparities in health care. Natl Acad Sci. 2003. ISBN: 0-309-15166-X, 432 pages, 6 × 9.

5. CCCK Online. n.d. Retrieved January 6, 2020, from https:// myonline.centralchristian.edu/news/2019/07/03/what-traumainformed-policing.

6. Oh H, DeVylder J, Hunt G. Effect of police training and accountability on the mental health of African American adults. Am J Public Health. 2017;107(10):1588-90.

7. Milam AJ, Furr-Holden D, Edwards-Johnson J, Webb B, Patton JW, Ezekwemba NC, et al. Are clinicians contributing to excess African American COVID-19 deaths? Unbeknownst to them, they may be. Health Equity. 2020;4(1):139-41. https://doi.org/10.1089/heq.2020.0015.

8. Laurencin CT, McClinton Aneesah (2020) The COVID-19 Pandemic: a Call to Action to Identify and Address Racial and Ethnic Disparities. Journal of Racial and Ethnic Health Disparities 7(3):398-402

Publisher's Note Springer Nature remains neutral with regard to jurisdictional claims in published maps and institutional affiliations. 